Research article

\title{
A Framework for Usability of e-Government Services in Developing Countries
}

\author{
Humphrey Anjoga, Sonny Nyeko and Mayoka Kituyi \\ NITA-Uganda, Kampala, Uganda \\ Makerere University Business School, Kampala, Uganda
}

Correspondence should be addressed to: Mayoka Kituyi; kimayoka@gmail.com

Received date: 4 October 2013; Accepted date: 15 October 2013; Published date: 15 September 2017

Copyright (C) 2017. Humphrey Anjoga, Sonny Nyeko and Mayoka Kituyi . Distributed under Creative Commons CC-BY 4.0

\begin{abstract}
The use of Information Communication Technology in carrying out government activities has become a common phenomenon in the recent years. In the late 1990s, information technological developments in the field of public administration culminated into the concept of eGovernment. Several benefits are presumed to be associated with E-Government services which basically translate to provision of direct services to users instead of/or in addition to traditional flow of paper work between the government and its citizens. However, despite these developments, most developing countries are yet to realize the full potential of e-Government initiatives. This study sought to examine the requirements for effective usability of eGovernment services using a quantitative survey. The requirements were then used to design a framework that would guide the effective usability of e-government services in developing countries. Findings indicate that the key requirements for e-Government service usability are provision of a noise free e-Government platform, articulation of e-Government goals and objectives to users, support for and prediction of future trends affecting e-Government initiatives, e-Government services being transferable across different contexts of application, support for system representation of strategic agendas and implementation efforts, provision of a functional representation of e-Government objectives and support for reusability and expandability of e-Government platforms. The paper proposes a framework that can be guide successful usability of e-Government services in developing countries.
\end{abstract}

Keywords: E-Government Services, Usability, Developing Countries, Uganda

\section{Introduction}

The use of Information Communication Technology (ICT) in carrying out government activities has become a common phenomenon in recent years. In the late 1990s, information technological developments in the field of public

Cite this Article as: Humphrey Anjoga, Sonny Nyeko and Mayoka Kituyi (2017)," A Framework for Usability of e-Government Services in Developing Countries ", Journal of Accounting and Auditing: Research \& Practice , Vol. 2017 (2017), Article ID 313796, DOI: 10.5171/2017.313796 
administration culminated into the concept of-Government. To date e-Government has been applied to support the unique activities of government, including Electronic Data Interchange (EDI), interactive voice response, voice mail, email, web service delivery, virtual reality, and key public infrastructure. Services such as Government to Citizen (G2C), Government to Government (G2G), and Government to Business (G2B) are synonymous in most countries (OCED, 2004; Bonham \& Seifert, 2003; Evans \& David, 2005). Several benefits are presumed to be associated with E-Government services which basically translate to provision of direct services to users instead of using the traditional flow of paper work between the government and its citizens (Ho, 2002; Netchaeva, 2002; Whitson and Davis, 2001; UN, 2002; UN 2001). These bring about savings in terms of money and time. A fullyfledged E-Government service is expected to provide users with 'one-stop shopping' (Ho, 2002) to access and transact the information needed via a government website that is tailored to provide information irrespective of the various functional units of that particular government agency. In developed countries, E-Government has improved efficiency, transparency and accountability functions. It has also provided convenient and faster access to services in addition to democracy and lower administrative costs (Netchaeva, 2002). However, despite these developments, most developing countries are yet to realize the full potential of $\mathrm{e}$ Government. Most initiatives have failed. Heeks (2003) notes that more than one-third of e-government initiatives in developing countries are total failures, half are considered to be partial failures while only one seventh are successes.

Many factors have been advanced to explain why governments in developing countries have failed to optimally use-Government services. Kumar (2006) for example points out that the existing service delivery systems in public institutions have institutional structures that do not allow optimal eGovernment service usability. There are also inappropriate models and/or frameworks to guide e-Government service usability. According to Gurp and Bosch (2001), a Framework is a partial design of an application in a given domain, leading towards its implementation. Frameworks can be classified as Application Frameworks and Domain Frameworks. Application Frameworks provide a whole range of functions required by any application, irrespective of its domain, such as a graphical user interface, database management or Internet connectivity while Domains support applications that belong to specific vertical domain such as Banking, Health, Transportation, or Public Services. In this study, we sought to examine the requirements for e-Government usability in public service delivery and develop a framework that will guide usability of eGovernment services in developing countries.

\section{E-Government Service Delivery Categories}

Although e-Government encompasses a wide range of activities and actors, three distinct sectors can be identified and explained as; Government to Citizen (G2C), Government to Government (G2G) and Government to Business (G2B). These are elaborated as follows:

\section{Government to Citizen (G2C)}

This sector is designed to facilitate citizen interaction with government as the primary goal of E-Government. It attempts to make transactions such as renewing licenses and certifications, paying taxes, and applying for benefits. G2C services are less time consuming and easier to carry out. G2C also often strives to enhance access to public information through the use of dissemination tools such as Websites and/or computer kiosks. This category of service delivery focuses on the ability of the government and citizen to communicate information to each other in an efficient manner using electronic format. Other applications are data 
submission online to the government and edemocracy.

\section{Government to business (G2B)}

Government-to-Business (G2B) initiatives receive a significant amount of attention, in part because of the high enthusiasm of the private sector and the potential for reducing costs through improved procurement practices and increased competition. The G2B sector includes both the sale of surplus government goods to the public, as well as the procurement of goods and services. A practical application in this category is the online submission of company data into government databases (OCED, 2004).

\section{Government to Government (G2G)}

This sector represents the backbone of EGovernment. Here governments at all levels must enhance and update their own internal systems and procedures before electronic transactions with citizens and businesses can be successful. G2G E-Government involves sharing data and conducting electronic exchanges between governmental actors. It involves both intra- and inter-agency exchanges at the national level, as well as exchanges between the national, provincial, and local levels (Bonham and Seifert, 2003). This sector aims at improving the efficiency of delivery when transacting information within the government itself, for example by using intranets for government employees, or with other governments. It allows the government to communicate efficiently by eliminating redundancies and duplication. Benefits such as crime detection like the ability to follow large exchanges of money via networks of banks, casinos and suspect organizations and charities may help the government to recover funds, trace criminals and predict terrorist activities (Evans and David, 2005).

\section{E-Government Service Usability}

Usability is the overall measurement of the satisfaction of interactions a user has with a product or system such as a Website, software application, mobile technology, or user-operated device. Usability becomes increasingly important as more and more information, products, and services become available through electronic means (Bury and Oud, 2004). Usability can also be regarded as "the extent to which IT affords an effective and satisfying interaction to the intended users, performing the intended tasks within the intended environment at an acceptable cost" (Sweeney et al., 1993). Usability focuses on the needs of the user by promoting a user-centered approach to website development which makes the task easier for the user. The success of a commercial or government site depends on its usability. When a company's site is not very accessible to users, they can easily find (almost) the same information on the other site. However, for websites of the government other options often do not exist (Aerts \& Gilis, 2005). Thus, citizens will have no other possibility than to use the system government implements. Therefore, the role of the citizen is crucial and should be involved in the design and implementation of these e-systems (Oostveen and Besselaar, 2005). Better still, the aspect of 'accessibility' cannot be neglected. Government officials should recognize equity and accessibility as important factors in the physical and virtual (e-) worlds. It is not sufficient to place information and services online if there are barriers to their usage among various sectors of society (West, 2003). Consequently, EGovernment solutions must include alternative delivery channels for people who can never use the most common process. These alternative delivery channels can also benefit all users who are temporarily unable to use the main E-Government channels (for instance due to power failures or system breakdown, or due to a user's temporary impairment) (Arch \& Hardy, 2005).

In terms of web services and resources, usability is important because according to recent research (User Interface Engineering, 2001) people cannot find the information they seek on Web-sites about $60 \%$ of the

Humphrey Anjoga, Sonny Nyeko and Mayoka Kituyi (2017), Journal of Accounting and Auditing: Research \& Practice, DOI: 10.5171/2017. 313796 
time. Similarly, research by Manning et al., (1998) revealed that the consequence of bad site design is that the site will lose repeat visits from $40 \%$ of the users. This can lead to wasted time, reduced productivity, increased frustration, and loss of repeat visits and revenue, thus increased training and increased support costs.

Nielsen (1993) points out that usability is not a one-dimensional concept, but includes a number of components including; Learnability i.e. ease of learning to use the system; Efficiency i.e. improved productivity; Memorability i.e. users being able to return to the system after some period of not having used it without having to relearn everything afresh; Errors i.e. how easy it is to recover from errors; Satisfaction i.e. the system being able to satisfying users.

Vassilakis et al.,(2003) identified four major requirements of usability as; provision of the appropriate forms through which users would submit in their information, implementation of input validation checks, forwarding of collected data to the back-end system processing, and collection and notification of the results to each user. Vassilakis et al., (2003) further note that post implementation issues such as user identification credentials (usernames and passwords) for authentication with limited administration privileges and sufficient management tools for user management, database backup and recovery, batch generation of personalized e-mail messages, statistics reports, etc are important. However, to succeed with one-stop government, the specific needs of the different user groups (i.e. citizens, businesses and other public administrations) need to be investigated and addressed. The ISO standards 13407 and 924 have been the basis for specifying the user requirements within E-Government:

a) Services relevant for the user group (e.g. functionality): It should be clear to the user what each service is good for and how it works (functionality).
Ideally, the user recognizes intuitively how to use the service (awareness), but additional help should be available if needed.

b) Technical aspects at the user's site (e.g. security): The user is expected to have and be able to use certain technology. In case of an online onestop-platform, the user is expected to have a browser and certain technical equipment. It should be mentioned that the level of technology demanded from the citizen should be as low as possible while the level for businesses and public authorities can be higher.

c) Reliability: The user should be able to rely on the way the system works and to count on its timeliness. Therefore, the system should be predictable, i.e. the user should not be surprised by the way the system reacts. Further, the system should inform the user that something is going on and what is going on (feedback). Finally, it should deliver the expected results within a reasonable, short time.

d) Multilingualism: The system should not be restricted to one single language. The user should be able to choose the language in which she/he wants to use the system. However, since multilinguality is a costly issue, a reasonable trade-off has to be defined for how many languages the system should offer in respect to the context it will be used.

\section{Usability Evaluation}

Usability evaluation examines how users react to and interact with Web systems. Evaluation involves the employment of usability metrics to focus on two specific aspects of the experiences of users: their perceptions and their interactions with the system (Hert, 2001). The first type of metric allows a user to express personal 
impressions of a resource, such as satisfaction, utility, value, helpfulness, benefits, frustration, and self-efficacy (Dalrymple \& Zweizig, 1992; Hert, 2001). The second type of metric provides a portrait of a user's interaction with a resource by monitoring the number of errors, the time necessary to complete specified tasks, and similar measures of the efficiency and effectiveness of the resource when being used (Hert, 2001).

An important fact also, confirmed by many experiments, is that nobody can foresee usability problems for a given user interface not even usability experts. Usability experts may predict many usability problems with a design, but about half of the predicted problems are false, in the sense that users do not feel they are problems. Worse still is that most usability experts miss about half of the problems that real users experience (Cuomo \& Bowen, 1994; Desurvire et al., 1992; Jeffries et al.1991). Only some kind of testing with real users can reveal the usability problems. In order to correct the problems therefore, there is a need to identify and correct such problems early enough during development stage.

\section{Developing e-Government services usability frameworks}

In the e-Government field there is a rapid growth in the development of e-services (Ancarini, 2005; Buckley 2003). Such an eservice is a public service mediated electronically through a user interface that is generally available. Public e-services can be used by citizens or company through G2C and G2B respectively. These users can be inexperienced and infrequent users of the public e-service. If e-services are to be used, they must be easy to use and be beneficial to the user. There exist several lists of usability design criteria. Examples of criteria lists are 10 Usability heuristics (Nielsen, 1993); Eight Golden Rules (Shneiderman, 1998); design guidelines for small screen devices (Kärkkäinen \& Laarni, 2002); Context-aware mobile applications (Hakkila \& Mantyjarvi, 2006) and Participatory Heuristic Evaluation (Muller et al., 1998). These lists are explicitly not web oriented.

Website usability has been a problem for eGovernment development. Although international guidelines on webpage development are provided by World Wide Web Consortium (W3C, 2009) to help website administrators develop usable websites, they are often not followed (Gwardak\&Pahlstorp, 2007). For example, Parajuli (2007) evaluated 17 websites of the Nepal government according to four criteria: transparency, interactivity, accessibility, and usability. Results regarding usability showed that it was not so easy to navigate or search information on the Nepal government websites because only 35 percent of websites provided a site map and 29 percent provided a search engine.

In literature, research related to any list belonging to the context of public e-services delivery is minimal. The importance of identifying different contexts is acknowledged by Henninger et al., (1995). They claim that "If the potential of usability guidelines as an interface design technique is to be fully realized, they need to be augmented with context-specific guidelines and examples that synthesize isolated guidelines into domain-specific solutions to design problems". However, ISO (1998), Nielsen (1999), SCANMIC model, and Hassan \& Li (2005) have presented criteria for designing e-service usability. This is illustrated in Table 1: 
Table 1: Usability criteria matrix

\begin{tabular}{|c|c|c|c|c|}
\hline \multirow[b]{2}{*}{ Criteria Dimensions } & \multicolumn{4}{|c|}{ Usability Criteria Models } \\
\hline & ISO 1998 & $\begin{array}{c}\text { Nielsen }(2003, \\
1999)\end{array}$ & $\begin{array}{l}\text { Teoh et al } \\
(2009)\end{array}$ & $\begin{array}{c}\text { Hassan \& Li's } \\
(2005)\end{array}$ \\
\hline Easy Navigation & $\mathrm{X}$ & $\mathrm{X}$ & $\mathrm{x}$ & $\mathrm{x}$ \\
\hline Accessibility & $\mathrm{x}$ & $\mathrm{X}$ & $\mathrm{x}$ & $\mathrm{x}$ \\
\hline Screen Design & $\mathrm{x}$ & $\mathrm{X}$ & $\mathrm{x}$ & $\mathrm{x}$ \\
\hline Media use & $\mathrm{x}$ & $\mathrm{X}$ & $\mathrm{x}$ & $\mathrm{x}$ \\
\hline Interactivity & $\mathrm{x}$ & $\mathrm{X}$ & $\mathrm{x}$ & $\mathrm{x}$ \\
\hline Consistency & $\mathrm{x}$ & $\mathrm{X}$ & $\mathrm{x}$ & $\mathrm{x}$ \\
\hline Content usefulness & $\mathrm{x}$ & $\mathrm{X}$ & $\mathrm{x}$ & $\mathrm{x}$ \\
\hline Customization & $\mathrm{x}$ & & & \\
\hline Ease to use & $\mathrm{x}$ & & & \\
\hline
\end{tabular}

\section{E-Government Frameworks}

There are different frameworks and/or models for e-Government. These were developed by international companies or expert people who have experience in EGovernment and can be categorized into four i.e. described models, maturity models, process models and E-Government frameworks (Shahkooh \& Abdollahi, 2007). Described models describe E-Government such as Broadcasting/Wider-Dissemination Model and Interactive-Service Model (Vikas, 2000). Maturity models present stages of EGovernment development which are used to evaluate E-Government implementations such as Delloite Model (Turban, et al., 2002). Process models present processes of EGovernment planning and show parameters and procedure of E-Government development planning such as Misra \& Dingra Model (2002) and Heeks Model (2001) and E-Government frameworks such as Wimmer framework (2002), and Garcia \& Pardo (2005) that guide the implementation and use of E-Government.

E-Government applications are usually set up for users external to public administration (citizens -G2C, businesses - G2B) as well as for internal users (G2G). Makolm (2006) points out that successful E-Government does not only use Information Technology and put administrative services on the internet but implies reengineering administrative processes, reorganizing and restructuring public organizations and shifting the focus towards a citizen and customer-centered service provision. However, this view considers usability after the whole systems development process.

Harold et al., (2001) suggests that systems are designed to be usable when there is a match between the product and the users under particular constraints and tasks. Usability is seen when the product is used and not when it is designed. So if we want to design better products, foresight has to be used. In many cases, usability comes in at the time of evaluation. Prototypes may be considerably advanced in development, so changes suggested by the results of evaluation may be too expensive to implement or could strongly resisted. This is because of the investment of time and effort in the existing system. Therefore to enhance the usability of an E-Government system, it is prudent to involve foresight so that usability is considered right away into the system development processes.

Many researchers; Petri and Lena (2005), Eyal (2009), Al-badiet al., (2010) note that software engineering is mainly concerned with the internal functionality of the product, while User-Centred Design (UCD) approach places the user, user tasks and user goals as the main concerns for the design and implementation of the product (Gould \& 
Lewis, 1985; Nielsen, 1993). Currently, specific usability practices are not included within software engineering models or in software engineering education and therefore, not well adopted in the industry. Beside the common on usability engineering, several studies (Carter 1999; Constantine 2001; Kane 2003; Battle 2005; Ferre et al., 2005; Zhang et al., 2005) have provided guidelines or proposed frameworks to assist developers incorporating usability activities into well-practiced and matured development models. Further, Vaki et al., (2005) investigated usability in the complete lifecycle of the creation of digital applications such as web applications to develop procedural guidelines with the aim of helping institutions to build usable web applications to reinforce and maintain solid and longterm relationships with their end users. These are categorised as Conception and planning, specification and design, implementation and operation and use.

\section{Description of the Research Methods Used}

Both quantitative and qualitative research methods were used. Qualitative methods were used to collect data from government officials who also double as citizens and/or stakeholders. Secondary data were gathered from relevant literature including textbooks, journal articles, e-Government magazines and unpublished reports/articles on eGovernment from companies and /or public libraries. Literature review involved selecting, reading and relating relevant usability studies, and translating the studies into one another. A number of different usability criteria models were studied synthesized and analyzed by tabulating criteria against different suggested models. The criteria that were found in all models qualified to be a criterion for the study. This method was used because it gives the possibility to establish the number and variety of properties, qualities and habits found in different studies under different environments and study populations.
To identify the requirements for developing the framework a self-administered questionnaire was used. A survey considered Heads of IT departments and one other staff selected randomly from each IT department of the 20 Uganda Government Ministries enlisted on the National IT Backbone project in Kampala. Kampala is the centre of most government ministries and has the highest population density in Uganda. In addition, 1 member of staff in the IT departments of each ministry was selected randomly. Therefore the total sample used was 40 . All the 40 questionnaires were returned and analyzed.

To design the framework for e-Government usability and public service delivery, a Unified Modeling Language (UML) tool was used. UML is object-oriented software used to design artifacts.

\section{Findings}

\section{Requirements for developing a Generic Framework for E-Government}

E-Government deployment is influenced by diverse factors. Consequently, in developing a generic framework, a set of criteria that should inform and shape what factors constitute the framework, its requirements, features, and how they are arranged and relate to each other is needed.

Data were collected on the requirements for successful usability of e-Government services using a 5 point likert scale i.e. $1=$ Strongly Disagree, 2=Agree, 3=Neutral, 4=Agree and $5=$ Strongly Agree. Descriptive means show that the respondents strongly agreed that for successful usability there should be provision of a noise free representation of eGovernment services (Mean=4.02); Enable identification and articulation of EGovernment goals and objectives (Mean=4.43); Identify the gap between the present and the future states of eGovernment deployment (Mean=4.51); Support prediction of future trends affecting e-Government initiatives (Mean=4.32); e- 
Government services should be transferable across different contexts of application (4.22); Support a system representation of strategic agendas and implementation efforts (Mean=4.17); Provide a functional representation of E-Government objectives (4.46); Support reusability and expandability of e-Government platforms (4.21). Table 2 presents the requirements for usability of eGovernment services:

Table 2: Requirements for usability of e-Government services

\begin{tabular}{|l|l|l|l|l|}
\hline Requirement & $\mathbf{N}$ & Min & Max & Mean \\
\hline Provide a noise free representation of e-Government services & 40 & 1 & 5 & 4.02 \\
\hline $\begin{array}{l}\text { Enable identification and articulation of E-Government goals and } \\
\text { objectives }\end{array}$ & 40 & 1 & 5 & 4.43 \\
\hline $\begin{array}{l}\text { Identify the gap between the present and the future states of e- } \\
\text { Government deployment }\end{array}$ & 40 & 1 & 5 & 4.51 \\
\hline $\begin{array}{l}\text { Support prediction of future trends affecting e-Government } \\
\text { initiatives }\end{array}$ & 40 & 1 & 5 & 4.32 \\
\hline $\begin{array}{l}\text { e-Government services should be transferable across different } \\
\text { contexts of application }\end{array}$ & 40 & 1 & 5 & 4.22 \\
\hline $\begin{array}{l}\text { Support a system representation of strategic agendas and } \\
\text { implementation efforts }\end{array}$ & 40 & 1 & 5 & 4.17 \\
\hline Provide a functional representation of E-Government objectives & 40 & 1 & 5 & 4.46 \\
\hline Support reusability and expandability of e-Government platforms & 40 & 1 & 5 & 4.21 \\
\hline
\end{tabular}

\section{Discussion of the requirements}

\section{Provide a noise free representation of $e$ - Government services}

A noise free representation of a variety of stakeholders is an ideal to a high level framework that has the ability to capture a more objective representation of EGovernment that can be shared and easily referenced across political, ideological, and technological boundaries with a common basis for informed discourse about issues relating to the E-Government agenda. Otherwise a significant amount of "noise" and interference generated by political, social, and technological factors and agendas, are injected into the process of identifying, analyzing, and deciding what projects and processes to adopt in executing the EGovernment program (Osborne \& Gaebler, 1992). Furthermore, the technical jargons, definitions and issues found in the IS/IT field also obscure the true situation (Luftman, 1996) which disconnect the points of view of key participants.
Enable identification and articulation of $E$ Government goals and objectives

Effective coordination and organization of an E-Government program requires a clear setting and understanding of goals and objectives. This is a significant act that an administration can undertake in the reform process (Osborne \& Gaebler, 1992). For maximum support and success, the vision must be shared and effectively communicated (Cufaude, 2003). This has a powerful effect on communication, understanding, commitment, integration and alignment of goals and objectives to different functional areas.

\section{Identify the gap between the present and the future states of e-Government deployment}

Understanding and identifying the gap between current and future states are key elements in the strategic management process and provide an effective way of monitoring the progress of E-Government 
initiatives. Mapping the progress from "the way things are now" to "the way things ought to be" also allows decision makers to weigh the potential progress of each area against the level of future development required by the E-Government vision. It can also assist policymakers and administrators in analyzing the potential benefits and impacts of committing resources and implementation effort as they engage in the planning process. Beyond the determination of success and failure, the mapping of current reality against the mission statement of the future also generates the energy for change.

\section{Support prediction of future trends affecting e-Government initiatives}

E-Government is a reform effort that is breaking new ground in many areas. For example, beyond the ability to access information and perform basic electronic transactions, citizens are demanding more customized products and services rather than acceding to the traditional public institution 'one size fits all' approaches (Osborne \& Gaebler, 1992). The emphasis of technology-enabled service delivery shifted towards providing the right systems and services that users need. Trends are towards increasing functionality, specialization, and integration (Bertelsmann, 2001). In addition, Strategic foresight, coupled with an understanding of the technology and application changes required, is essential to managing internal and external operational and strategic constraints. Consequently, a framework for E-Government, acting as a diagnostic tool, should be helpful in predicting the impact of future trends and requirements.

\section{E-Government Services Should Be Transferable Across Different Contexts of Application}

Every nation has its own functional, social, and administrative objectives to fulfill. As a result, each nation's vision will differ with respect to the strategic priorities of the policymakers and the jurisdiction they represent, giving a unique flavor and direction for each E-Government endeavor. Therefore, every E-Government program should be viewed and assessed with respect to its context of application (Corrocher \& Ordanini, 2002). A greater understanding of motivations and resulting patterns of development in different settings can facilitate the process of comparing approaches and provide a rational means of setting the reform of public administration on course for efficiency and transparency, with clear orientation towards its citizens (Bertelsmann, 2001). It is vitally important to distinguish patterns of development and motivations for E-Government and identify transferable elements. This would be invaluable; given E-Government is an evolving and pioneering effort where all countries can be considered as being in the early stages of development (Pacific Council on International Policy, 2002). A generic framework that encapsulates these principles would go a long way to improve the discourse about how E-Government is being developed across different jurisdictions and contexts.

\section{Support A System Representation of Strategic Agendas And Implementation Efforts}

A system representation of E-Government is required to capture the system's nature of the concept. Systems are one of the common units of analyses within the E-Government endeavor. Systems must be balanced across the implementation and are also an area where mapping efforts can be applied and gaps can be identified. The impact and effects of future needs and requirements also have a direct effect on the E-Government systems. Given that the operation of E-Government depends significantly on the effective management of a variety of systems, a generic framework should capture details of electronic government at this level.

Provide A Functional Representation of EGovernment Objectives 
Another common unit of analysis is at the functional level. Goals, objectives, and future needs and requirements are typically articulated in form of functional capacities. In addition, gaps in functionality provide the first indicators that the realization of the EGovernment vision is not on course. Functional capacities are also used in the comparison of international efforts. To account for these realities the framework must maintain an ability to identify functional capabilities at a high level in a way that reflects the primary motivations and objectives of the overall E-Government program. Therefore, a functional representation of E-Government is a necessary requirement, supporting several types of analytical efforts. High-functioning government web portals are designed to search, classify, present and integrate relevant information. Applications integrate data at three levels of complexity: (1) information publishing and linking of existing websites, (2) single agency transactions, and (3) transactions requiring integration of multiple agencies (Author, 2001). The highest functioning web portals have complete system integration across agencies whereas portals with the lowest level of functionality provide little more than access to forms and static bits of information. High-functioning portals create a true onestop shop for citizens in terms of: usability, customization, openness, and transparency.

\section{Support Reusability and Expandability of E-Government Platforms}

The analysis and consideration of EGovernment also have an implicit requirement for reusability and expandability. The mapping of current development against the future is an ongoing effort and must be periodically reviewed and revised. As a result, the generic framework also must be able to capture new data and information about new developments on an ongoing basis. It must classify and describe the ongoing activities at a high level and provide a functional representation that can aid in the planning and implementation process. With regards to the changing nature of E-Government, the framework should act as a "sliding window" that reveals the relationship between current initiatives and the overall vision. Figure 1 shows the proposed framework for usability of eGovernment services in developing countries: 


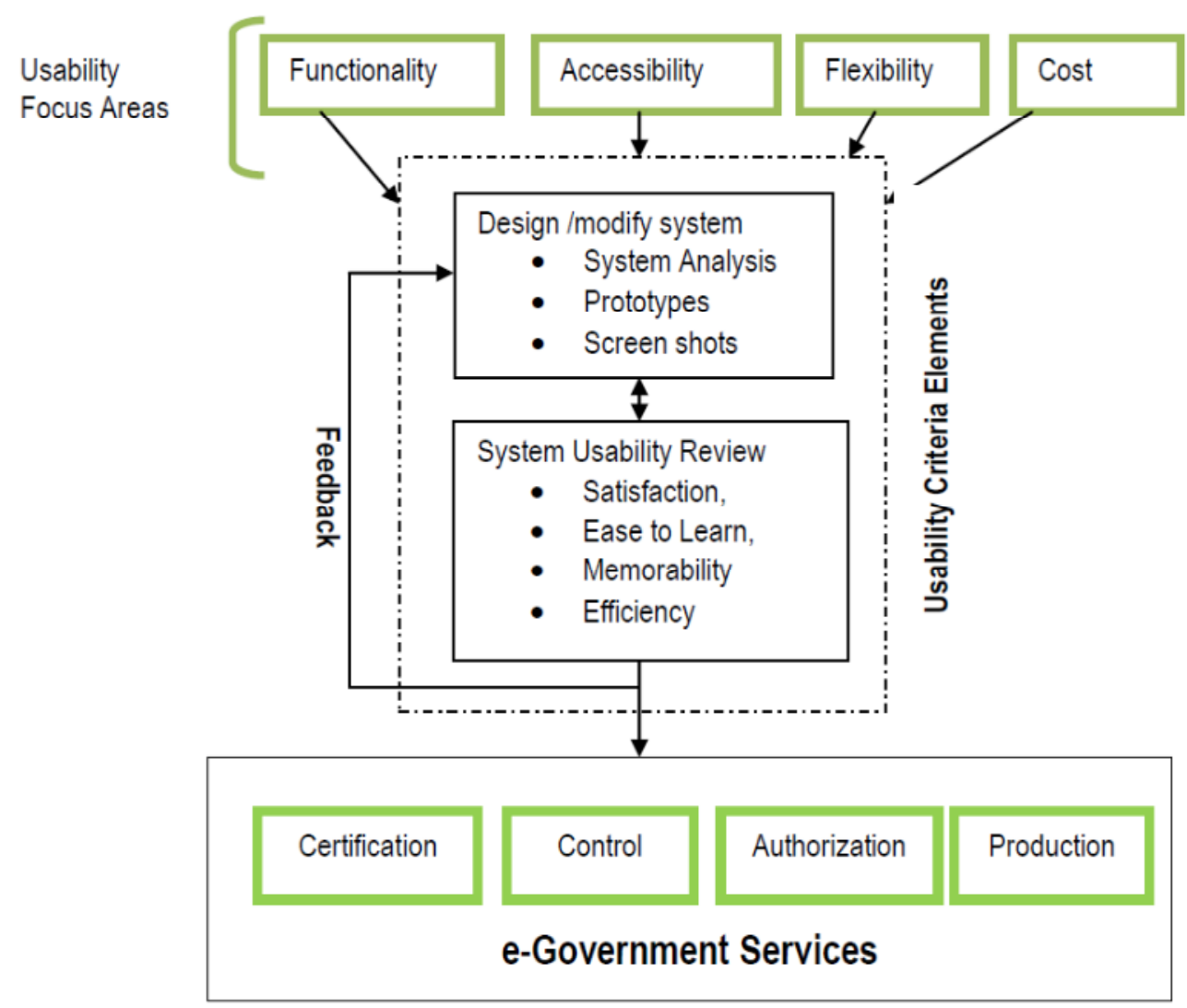

Figure 1: Framework for usability of e-Government services

\begin{abstract}
Discussion, Conclusion and Recommendations

E-Government usability empowers Government stakeholders through public access to information resources and good governance. Many studies on usability have looked at usability from the viewpoint of the technology itself as compared to examining it from the user's perspective especially on the use of e-Government systems.
\end{abstract}

This research dealt with identifying the requirements from users which were used to design an e-Government services usability framework for developing countries. The first objective of the study was to identify the requirements for developing a framework for e-Government usability. Findings indicated that functionality dimensions e.g. service delivery mission/vision, bridging gaps of traditional methods, accepted web development Standards, motivation and rewarding systems, flexibility and compatible user numbers; cost dimensions included initial investment, administration and maintenance, training, access, clarity, and awareness; flexibility requirements such as capturing new data and developments, review and control, multilingual, and speed of feedback; accessibility requirements such as alternative service delivery channels, navigation, and indiscriminate access and usability requirements such as ease to learn, error tolerance, satisfaction, efficiency, and consistency of user interfaces (memorability). Usability was also influenced by reliability and error tolerance, efficiency and consistency of user interfaces. The findings are in agreement with the studies of 
Shackle (1991), Nielsen (1999) and Hakkila \& Mantyjarvi (2006).

About the criteria for designing eGovernment usability frameworks, findings from literature indicate over 68 criteria for web usability. Hassan and Li (2001) identified web usability criteria from content analysis of a list of over 65 criteria which he grouped into seven categories such as screen design, content, accessibility, navigation, media use, interactivity and consistency (SCANMIC Model). Other criteria lists included 10 Usability heuristics (Nielsen, 1993); Eight Golden Rules (Shneiderman, 1998); design guidelines for small screen devices (Karkkainen \& Laarni, 2002); Context-aware mobile applications (Hakkila \& Mantyjarvi, 2006) and Participatory Heuristic Evaluation (Muller et al., 1998). The criteria for E-Government usability are derived which are navigation, accessibility, screen design, media use, consistency, interactivity and content usefulness. These findings are in conformity with the findings of ISO (1998), Hassan and Li (2001) and Toah et al., (2009). A procedure for the development of web applications was adopted from Calimere Usability guidelines because they reinforce and maintain solid and long-term relationships with their end users (Vaki et al, 2005).

The proposed e-Government usability framework is simple, easy to use and systematic. The framework was designed based on the requirements gathered and analysed. The process of developing the framework focused on the theory of systems usability. The framework can support the successful usability of e-government services, especially in developing countries like Uganda.

\section{Limitations of the Study}

The research was limited to identifying the requirements and designing e-Government service usability framework. The organisations that were covered were mainly Ugandan government Ministries. Results could be different if the study were conducted, say, including government agencies, citizens, NGOs, private sector or in other countries. The study population was limited by resources, and even the questions were limited to e-Government usability requirements and metrics/measures. Further, the framework was not validated. Framework development was not incorporated with other service delivery channels and forms of government like Mobile Government; SMS based public service delivery channels.

\section{Recommendations}

Usability is an important factor in the deployment of a one stop Government approach for Electronic public service delivery in form of Government 2 Citizens (G2C), Government to Business (G2B) and Government to Government (G2G) in developing countries like Uganda. International Development partners such as United Nations, World Bank etc emphasize implementation of E-Government to enhance good governance and curb corruption. Ensuring E-Government usability through development of easily accessible, usable and low cost systems is vital. Consideration of usability requirements and criteria in deployment of E-Government services is recommended. The framework presented in this study provides a comprehensive guideline for the implementation and deployment of usable E-Government systems in different Ministries, but it is not exhaustive, for the ever changing usability requirements and technological environments. Furthermore, the usability requirements and criteria lists have to be updated. A more detailed and expanded survey could be taken since the study involved only 2 respondents from each of the 20 Ministries in Uganda. Involvement of other Government Agencies such as Uganda Revenue Authority, Electro Commission, and National Information Technology AuthorityUganda among others could earn the list more weight and make the framework more usable. 
Another possibility may be to try building a unified set of metaphors (or symbols) to be used on websites worldwide that are common to all countries, fully understood and do not offend anybody. This would resemble what traffic engineers/police managed to do in regards to the traffic/road rules or the "Highway Code" for road navigation and might reduce the work of localising websites since many features/icons would be the same.

For effective usability of e-government services in developing countries, we recommend that e-Government platform be noise free and should articulate their goals and objectives to users. Further, the egovernment services should be transferable across different contexts of application and should support system representation of strategic agendas and implementation efforts. The platforms should provide functional representation of e-Government objectives and support for reusability and expandability of e-Government services.

\section{References}

1. Ancarini A (2005). Towards quality eservice in the public sector: The evolution of websites in the local public service sector, Managing Service Quality, Vol. 15 (1)

2. Author, Creating and implementing an EGovernment portal solution: Requirements, solution options and business model considerations, IBM Global Industries 2001

3. Bonham G. M. and Seifert, J. W. (2003) the transformative potential of eGovernment in transitional democracies, Public Management. Electronic journal Issue № 2. 22, October 2003

4. Buckley J (2003). E-service quality and the public sector, Managing Service Quality, Vol 13

5. Bury. S. and Oud J. (2004), Usability testing of an online information literacy tutorial, Retrieved on 11.8.2008 from www.emeraldinsight.com/0090-7324.htm
6. Cufaude, J. (2003). Creating the future while managing the present. Association Management

7. Cuomo, D.L. \& Bowen, C.D. (1994): Understanding usability issues addressed by three user-system interface evaluation techniques, interacting with Computers, Vol.6

8. Desurvire, H.W., Kondziela, J.M \& Atwood, M.E. (1992): What is gained and lost when using evaluation methods other than empirical testing, Proceedings of $\mathrm{HCI}$ 92, Cambridge University Press.

9. Evans, D., and David C.Y. (2005).EGovernment: An analysis for implementation: Framework for understanding cultural and social impact, Government Information Quarterly

10. Garcia J. R., T. A. Pardo (2005) EGovernment success factors: Mapping Practical tools to theoretical foundations, Government Information Quarterly

11. Gurp J.V. and Bosch J. (2001) Design, Implementation and Evolution of Object Oriented Frameworks: Concepts and Guidelines, Journal of Software-Practice and Experience, volume 31

12. Gwardak, L. \& Påhlstorp, L. (2007) Exploring Usability Guidelines for Rich Internet Applications. Masters' thesis Department of informatics, Lund University

13. Harold T., P. Cairnsand J. Matt (2001), Usability Analysis with Markov Models

14. Hassan, S., and Li, F. (2005) Evaluating the usability and content usefulness of websites: a benchmarking approach, Journal of Electronic Commerce in Organizations, 3(2)

15. Heeks, R. (2003). Most e-Governments with e-Government for development fail: how can risks be reduced? In i-Government Working Papers, Paper no. 14.

16. Heeks R, (2001) Building E-Governance for development: A framework for National 
and Donor Actions, working paper, N0.12, ISDPM, university of Manchester, Manchester

17. Henninger, S., Haynes K., and Reith M.W. (1995) A framework for developing experience-based usability guidelines. In Proceedings of the 1st conference on Designing interactive systems: processes, practices, methods, \& techniques. Ann Arbor, Michigan, United States: ACM.

18. Ho, A.T. (2002) Reinventing local governments and the e-Government initiative, Public Administration Review, Vol 62

19. ISO (1998) Ergonomic requirements for office work with visual display terminals (VDTs), Part 11, Guidance on usability, ISO

20. ISO (1999) Human-centered design processes for interactive systems, International Standards Organization

21. Jeffries, R., Miller, J.R., Wharton, C., and Uyeda, K.M. (1991) User interface evaluation in the real world: A comparison of four techniques, $\mathrm{CHI}^{\prime} 91$ Proceedings

22. Luftman, J.N. (1996) competing in the information age: Strategic alignment in practice, Oxford University Press.

23. Makolm J. (2006) A Holistic Reference Framework for e-Government: The Practical Proof of a Scientific Concept, Proceedings of the 39th Hawaii International Conference on System Sciences

24. Misra D., C. A. Dhingra (2002)EGovernment Maturity Model, National Information Center, Department of Information Technology, New Dehli, Electronic information planning Journal

25. Muller M J, Matheson C, Gallup R. (1998) Methods and Tools: participatory heuristic evaluation. In Interactions

26. Netchaeva, I. (2002). E-Government and e-democracy: A comparison in the North and
South. Gazette' the International Journal for Communication Studies, Vol 64 No 5

27. Nielsen J (1993) Usability Engineering, Boston, Academic Press. XIV, 362.

28. Nielsen, J. (2003). Usability 101: Introduction to Usability. Retrieved March 8, 2008, from useit.com: http://www.useit.com/alertbox/20030825.ht $m l$

29. Nielsen, J. (2000) Designing Web Usability: The Practice of Simplicity, Indianapolis, New Riders Publishing.

30. OECD (2004). ICT diffusion to business, Committee for information, computer and communications policy, DSTI/ICCP/IE (2003)7/FINAL, 5 May 2004

31. Osborne, D., \&Gaebler, T. (1992) Reinventing government: How the entrepreneurial spirit is transforming the public sector, New York: Plume

32. Pacific Council on International Policy (2002) Roadmap for e-Government in the developing world: 10 questions eGovernment leaders should ask themselves, Report of the Working Group on e-Government in the developing world

33. Parajuli, J. (2007) A content analysis of selected government websites: A case study of Nepal, The Electronic Journal of $e$ Government Vol. 5, No. 1

34. Shahkooh K. A., A. Abdollahi (2004) A strategy-based model for e-Government planning, The Second International MultiConference on Computing in the Global Information Technology, French Caribbean, March 2007.

35. Shneiderman B (1998) Designing the user interface: Strategies for effective human computer interaction. 3rd ed. Reading, Mass: Addison Wesley Longman XIV, 639. 
36. Turban E. (2002) Electronic commerce 2002, a managerial perspective, 2nd edition, Prentice Hall

37. UN (2001) E-Commerce and Development Report: Prepared by United Nations Conference on Trade and Development, United Nations, New York \& Geneva, 2001. Internet Edn:

38. UN(2001) Benchmarking e-Government: A global perspective - Assessing the progress of the UN member states, United Nations, Division for Public Economics and Public Administration \& American Society for Public Administration

39. Vikas N. (2000) Networking Networks for Empowerment and Governance, retrieved on
23-Sep-10 http://www.cddc.vt.edu/digitalgov/gov-eparticipation-model.html

40. W3C (World Wide Web Consortium) (2009) W3C Web Standard Defines Accessibility for Next Generation Web, http://www.w3.org/2008/12/wcag20-

pressrelease.html, retrieved 19 Mar 2009

41. Whitson, T., and Davis L., (2001) Best practices in electronic government: Comprehensive electronic information dissemination for science and technology, Government Information Quarterly, Vol 18 No 2

42. Wimmer A. (2002) A European Perspective towards online one stop government: the eGov project, Journal of commerce Research and Application

Humphrey Anjoga, Sonny Nyeko and Mayoka Kituyi (2017), Journal of Accounting and Auditing: Research \& Practice, DOI: 10.5171/2017. 313796 